\title{
Energy consumption modeling during dairy sewage pretreatment
}

\author{
Wojciech Dąbrowski ${ }^{1,}$, Radosław Żyłka, Paweł Malinowski, and Dariusz Boruszko \\ ${ }^{1}$ Białystok University of Technology, Faculty of Civil and Environmental Engineering, Department of \\ Technology in Environmental Protection and Engineering, ul. Wiejska 45A, Białystok, Poland
}

\begin{abstract}
The research was conducted in a dairy WWTP located in northeastern Poland with the average flow of $546 \mathrm{~m}^{3} \mathrm{~d}^{-1}$ and PE 11500 in 2016. Energy consumption was measured with the help of Lumel 3-phase network parameter transducers installed within the plant. The modeling was conducted based on the quantity and quality of raw sewage, after its screening, averaging and dissolved air flotation. The following parameters were determined: $\mathrm{BOD}_{5}, \mathrm{COD}, \mathrm{N}$-total and P-total. During the research period, 15 measurement series were carried out. Pollution loads removed in primary treatment varied from 167.0 to $803.5 \mathrm{kgO}_{2} \mathrm{~d}^{-1}$ and 1205.9 to $10032 \mathrm{kgO}_{2} \mathrm{~d}^{-1}$ for $\mathrm{BOD}_{5}$ and COD respectively. The energy consumption share during dairy pretreatment in relation to the total energy consumption was in the range from 13.8 to $28.5 \%$ with the mean value of $18.7 \%$ during the research period. Energy consumption indicators relating to removed pollution loads for primary treatment were established with the mean values of 0.74 and $0.83 \mathrm{kWhkg}^{-1} \mathrm{~d}^{-1}$ for BOD 5 and COD respectively. An attempt was made to determine the influence of raw sewage characteristics and pretreatment efficiency on energy consumption of the object. A model of energy consumption during pretreatment was estimated according to the experimental data obtained in the research period. It was modeled using the linear regression model and principal component analysis.
\end{abstract}

\section{Introduction}

High demand for Polish dairy products on the global market means significant increase of milk production. The amount of milk produced in Poland raised from 11575 million liters in 2005 to 12859 million liters in 2015. Podlaskie Voivodeship is an absolute leader of milk production in reference to 1 ha of agricultural land. The milk produced in 2015 amounted to $2424 \mathrm{lha}^{-1}$ whereas the average value of this indicator within the whole country was $884 \mathrm{l} \cdot \mathrm{ha}^{-1}[1]$. A continuous increase of the amount of produced milk results in larger amounts of post-production sewage which requires treatment. Dairy sewage, as a product of cleaning technological lines after the production of milk powders, fat products and cheese, is characterized by high content of organic pollution, fat and grease. Such sewage content determines the usage of intensive mechanical pretreatment prior to biological treatment, which is most often conducted based on sewage averaging and dissolved air flotation (DAF).

\footnotetext{
*Corresponding author: dabrow@pb.edu.pl
} 
The research previously conducted in that field has shown that electric energy consumption during pretreatment process constitutes $18 \%$ of the total energy consumption in the facility [2]. It was also proven by the analysis of 601 wastewater treatment plants conducted by Longo et al. [3] in which the achieved percentage share of pretreatment in the total energy consumption ranged between 5 and $18 \%$. The authors of the research conducted in Irish municipal wastewater treatment plants report this value at $1.8-9.1 \%$ [4]. It constitutes a substantial part of the costs of energy consumption of a facility. Additionally, the environmental issue should be taken into consideration. Parravicini et al. [5] state that in two analyzed models of municipal wastewater treatment plants, electric energy consumption was responsible for even $59.9 \%$ of the facility's total carbon footprint. It has encouraged the authors to make an attempt at creating a mathematical model of electric energy consumption during dairy sewage pretreatment. The purpose of devising such a model is to determine the influence of electric energy consumption of pretreatment devices, in reference to removed pollutants load, on the total energy consumption in the facility. The obtained model might serve to optimize the costs of industrial wastewater treatment.

In the course of the research, electric energy consumption by particular subsystems of the pretreatment unit and the removed pollutant loads were determined. It allowed to establish energy consumption indicators in reference to $1 \mathrm{~kg}$ of removed load. A mathematical model was designed on the basis of the research data from 12 measurement series conducted from January to June 2016.

\section{Material and methods}

\subsection{Dairy WWTP characteristics and evaluation of energy consumption}

Bielmlek sewage treatment plant applies sequential flow. The average sewage flow in 2016 was $546 \mathrm{~m}^{3} \mathrm{~d}^{-1}$, with the personal equivalent (PE) of 11500 . The sewage treatment process has two phases: mechanical and biological. Pretreatment is completed through filtering through a sieve with the diameter of $6 \mathrm{~mm}$, sedimentation with the use of a grit chamber, averaging in an averaging tank, and pressure flotation supported by adding coagulants and aqueous solution of polyelectrolytes. Additionally, the mechanical treatment unit consists of pumps, mixers and primary aeration system in the averaging tank. Biological treatment is carried out in two sequence batch reactors (SBR). Treated sewage is discharged directly to a reception tank - the river Biała. Sewage sludge generated in the process is subjected to mechanical dewatering and used as fertilizer (Fig. 1).
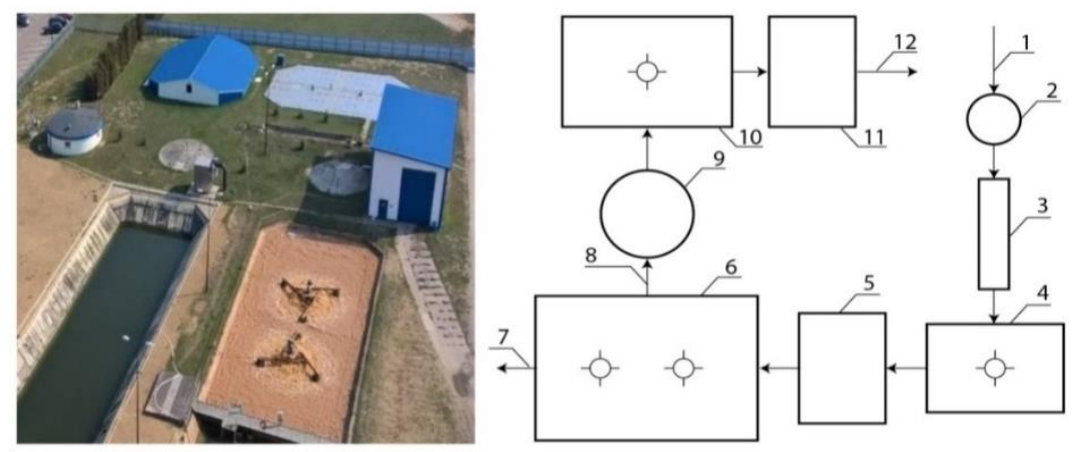

Fig. 1. View and flow diagram of Bielmlek WWTP; 1 - raw wastewater, 2 - screen, 3 - sand trap, 4 - averaging tank, 5 - DAF flotator, 6 - SBR reactors, 7 - treated wastewater, 8 - excessive sludge, 9 - gravity thickener, 10 - aerobic stabilization tank, 11 - screw press, 12 - dewatered sludge. 
The installed power of the treatment plant is $234.7 \mathrm{~kW}, 27.1 \%$ of which is constituted by pretreatment devices (Table 1). It should be mentioned that the grit chamber is a device with gravitational flow and manual sand discharge and for that reason it was not included in the study.

Sewage quality tests were conducted in S.M. Bielmlek laboratory. The sewage samples were collected as average values from a work shift in the production plant. Parameters such as $\mathrm{BOD}_{5}, \mathrm{COD}, \mathrm{N}$-total and $\mathrm{P}$-total were determined in the samples. The research was completed in 12 measurement series, during which electric energy consumption was monitored for both the whole facility and its individual parts.

Table 1. Power installed of Bielmlek WWTP.

\begin{tabular}{|c|c|c|}
\hline Item & Power installed [kW] & Percentage share of total [\%] \\
\hline Pretreatment: & 63.6 & 27.1 \\
\hline screen & 3.5 & 1.5 \\
\hline DAF & 19.3 & 8.2 \\
\hline pumps & 22.4 & 9.5 \\
\hline mixers & 7.4 & 3.2 \\
\hline blower & 11 & 4.7 \\
\hline Biological treatment & 104.5 & 44.5 \\
\hline Sludge management & 56.6 & 24.1 \\
\hline Air deodorization & 10 & 4.3 \\
\hline In total & 234.7 & 100 \\
\hline
\end{tabular}

\subsection{Energy consumption measurement system}

Installed within the plant, Lumel 3-phase network parameter transducers were used to measure energy consumption. The current transformers send signals, which are then received by the transducers. Precise measurement is possible thanks to current transformers connected to every single electric device within a plant. Supervisor control data system (SCADA) collects the information from the current transformers and makes it possible to view the results online, archive and process them, as well as to control the wastewater treatment process.

\subsection{Statistical model}

Statistical analysis was performed using Principal Component Regression (PCR) [6]. It is a two-step method. In the first step, 5 original input variables (loads of: $\mathrm{BOD}_{5}, \mathrm{COD}, \mathrm{N}$-total, P-total and flow) are normalized to zero mean and unit variance. After normalization, the variables are transformed linearly(or equivalently - rotated) by performing principal component analysis [7], to set of principal components (PC) - new variables (1).

$$
x_{i}^{\prime}=\frac{x_{i}-\mathbf{1} \mu_{i}}{\sigma_{i}} \quad P C_{j}=\sum_{i=1}^{5} a_{j i} x_{i}^{\prime}
$$

where: $i, j$ - indexes (from 1 to $n$ ); $x_{i}$ - original independent variable along with its normalization factors - mean $\mu_{i}$, and standard deviation $\sigma_{i} ; 1$ - vector of ones; $x_{i}^{\prime}$ - normalized independent variable; $P C_{j}$ - j-th principal component; $a_{i j}$ - linear coefficients of PCA transformation 
Due to the aforementioned normalization, the total variance (sum of variable variances) of the transformed dataset is equal to its dimensionality (5). Each additional PC, given the previous ones, is a direction that is orthogonal to them and maximizes the remaining variability of the transformed dataset. New variables are also not correlated - they are independent of each other. The second step is the standard linear regression with energy consumption $E$ as a dependent variable. For the analysis, only selected subset of PCs that cumulatively reflects more than $90 \%$ of dataset variance are taken as independent variables. PCs whose linear regression coefficients were statistically insignificant (at 5\% significance level) were iteratively removed from the calculated model until no such components were left.

$$
\begin{gathered}
E=\alpha_{0}^{\prime}+\sum_{k \in \operatorname{sel}(j)} \alpha_{k}^{\prime} P C_{k} \quad E=\alpha_{0}+\sum_{i=1}^{5} \alpha_{i} x_{i} \\
\alpha_{0}=\alpha_{0}^{\prime}-\sum_{i=1}^{5} \frac{\mu_{i}}{\sigma_{i}}\left(\sum_{k \in \operatorname{sel}(j)} \alpha_{k}^{\prime} a_{k i}\right) \quad \alpha_{i}=\frac{1}{\sigma_{i}} \sum_{k \in \operatorname{sel}(j)} \alpha_{k}^{\prime} a_{k i}
\end{gathered}
$$

where: $k$-index (over selected $\operatorname{sel}(j)$ principal components); $\alpha_{k}^{\prime}, \alpha_{i}-$ linear coefficients of the regression for: principal components (estimated) and original variables (calculated from estimations using).

The final model (2) will be presented in 2 forms: using selected PCs and in the original variables space. While the coefficients for the selected PC are directly estimated by regression, the coefficients for the original variables (3) can be calculated from estimations and transformation (1).

PCR offers a number of benefits over usual linear regression in input variable space[6]. Due to normalization, it is insensitive to the scale of the original variables. Due to decorrelation, it is more numerically stable. It offers dimensionality reduction - only a given subset of PCs, reflecting most of the dataset variability, could be used in regression model, making a starting model simpler. Effectively, PCR can explore the original problem space (the dataset) in its more natural dimension, that is usually lower than the number of original input variables.

\section{Results and discussion}

\subsection{Energy consumption ratio}

The research results were presented in Table 2. Pretreatment devices took on average $217.5 \mathrm{kWhd}^{-1}$ of electric energy, which was almost equal to the energy intake of sewage treatment devices, which consumed on average $230.3 \mathrm{kWhd}^{-1}$. Among the pretreatment devices, pumps and mixers were responsible for the highest electric energy intake which was 76.2 and $73.7 \mathrm{kWhd}^{-1}$ respectively. Pretreatment energy consumption indicators, in relation to $1 \mathrm{~kg}$ of the removed substance, reached the highest average value of $132.32 \mathrm{kWhkg}^{-1}$ for total phosphorous. Removing $1 \mathrm{~kg}$ of organic substance expressed as $\mathrm{BOD}_{5}$ and $\mathrm{COD}$ required respectively 0.74 and $0.83 \mathrm{kWh}$ of electric energy. In comparison, in 607 Slovakian municipal wastewater treatment plants analyzed by Bodík and Kubaská [8], 2.27 kWh was the average amount necessary to remove $1 \mathrm{~kg}$ of $\mathrm{BOD}_{5}$. During the research period the whole facility consumed on average $1132.7 \mathrm{kWd}^{-1}$ with the biggest share belonging to biological treatment, which was on average at $565.3 \mathrm{kWhd}^{-1}$. Energy indicator referred to $1 \mathrm{~m}^{3}$ of treated sewage fluctuated between 1.53 and $3.3 \mathrm{kWhm}^{-3}$ with the average value of $2.31 \mathrm{kWhm}^{-3}$. In comparison, in municipal wastewater treatment plants located in the USA, the indicator 
varies between $0.086-1.119 \mathrm{kWhm}^{-3}$ [9], whereas in the Chinese city of Shenzhen it is at $0.20 \pm 0.06 \mathrm{kWht}^{-1}[10]$.

Table 2. Values of energy consumption (E) and energy consumption indicators (EI).

\begin{tabular}{|c|c|}
\hline Item & Mean value (range) \\
\hline \multicolumn{2}{|l|}{ Pretreatment } \\
\hline $\mathrm{E}\left[\mathrm{kWhd}^{-1}\right]$ & $217.5(119.8-435.8)$ \\
\hline screen & $1.2(0.2-3.5)$ \\
\hline DAF flotator & $29.6(8.7-58.6)$ \\
\hline pumps & $76.2(29.6-103.6)$ \\
\hline mixers & 73.7 (44.4-95.7) \\
\hline blower $^{*}$ & 36.9 \\
\hline $\mathrm{EI}_{\mathrm{BOD} 5}\left[\mathrm{kWhkg}^{-1}\right]$ & $0.74(0.21-1.89)$ \\
\hline $\mathrm{EI}_{\mathrm{COD}}\left[\mathrm{kWhkg}^{-1}\right]$ & $0.83(0.12-3.03)$ \\
\hline $\mathrm{EI}_{\mathrm{N}}\left[\mathrm{kWhkg}^{-1}\right]$ & $13.70(4.38-32.03)$ \\
\hline $\mathrm{EI}_{\mathrm{P}}\left[\mathrm{kWhkg}^{-1}\right]$ & $132.32(23.47-494.52)$ \\
\hline $\mathrm{EI}_{\mathrm{Q}}\left[\mathrm{kWhm}^{-3}\right]$ & $0.43(0.26-0.77)$ \\
\hline \multicolumn{2}{|l|}{ Biological treatment } \\
\hline $\mathrm{E}\left[\mathrm{kWhd}^{-1}\right]$ & $565.3(371.5-838.0)$ \\
\hline \multicolumn{2}{|l|}{ Sludge treatment } \\
\hline $\mathrm{E}\left[\mathrm{kWhd} \mathrm{d}^{-1}\right]$ & $230.3(118.4-431.9)$ \\
\hline \multicolumn{2}{|l|}{ Air deodorization ${ }^{*}$} \\
\hline $\mathrm{E}\left[\mathrm{kWhd}^{-1}\right]$ & 28.2 \\
\hline \multicolumn{2}{|l|}{ Other $^{+}$} \\
\hline $\mathrm{E}\left[\mathrm{kWhd}^{-1}\right]$ & $91.5(70.2-127.1)$ \\
\hline \multicolumn{2}{|l|}{ In total $W W T P$} \\
\hline $\mathrm{E}\left[\mathrm{kWhd}^{-1}\right]$ & $1132.7(784.3-1537.1)$ \\
\hline $\mathrm{EI}_{\mathrm{Q}}\left[\mathrm{kWhm}^{-3}\right]$ & $2.31(1.51-3.13)$ \\
\hline $\begin{array}{r}\text { due to periodic and irregular } \\
\text { range }\end{array}$ & $\begin{array}{l}\text { of device during research perioc } \\
\text { termined }\end{array}$ \\
\hline
\end{tabular}

In the course of calculations, the percentage share of the pretreatment devices in the total electric energy consumption and electric energy consumption by pretreatment itself were established (Fig. 2). In the hierarchy of the most energy consuming devices of the technological line, pretreatment comes third with the share of $19 \%$. It correlates with the authors' results of the research conducted in dairy and meat wastewater treatment plants, where the share of pretreatment devices in the total energy intake was $17 \%$ [11]. Among pretreatment devices, DAF flotation is worth noticing for its low share of electric energy consumption at $14 \%$. It should be mentioned that DAF flotation during the research period was responsible for respectively $47.6 \%, 37.6 \%, 47.6 \%$ and $33.0 \%$ of the total $\mathrm{BOD}_{5}, \mathrm{COD}$, $\mathrm{N}_{\text {tot. }}$ and $\mathrm{P}_{\text {tot. }}$ removed loads. 

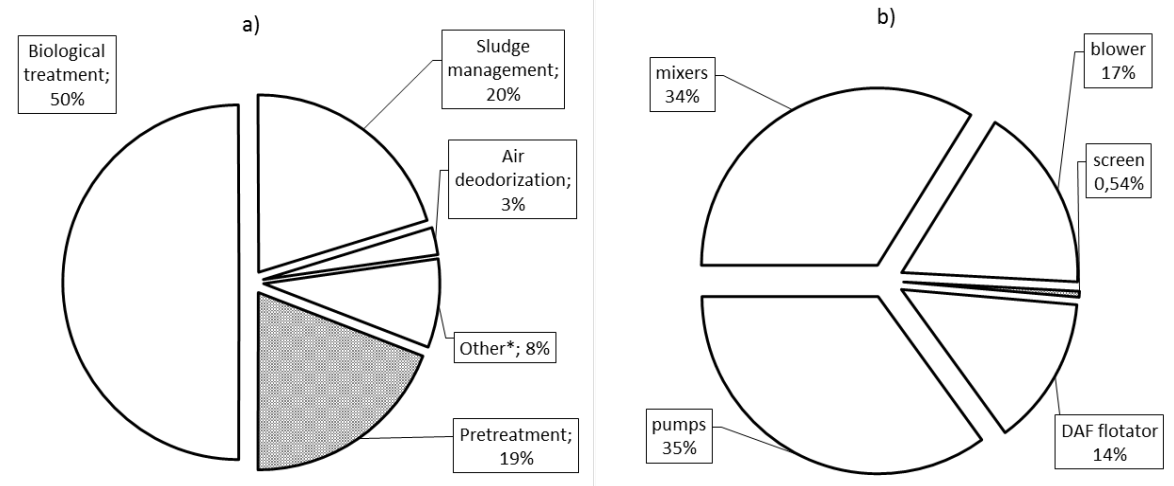

Fig. 2. Percentage share of energy usage during research period; a) whole WWTP, b) pretreatment; *staff's welfare facilities, lighting and measuring equipment.

\subsection{Model of energy consumption due to PCR}

Statistical analysis was performed in R environment, version 3.3.0 [12]. Energy consumption was modeled using the PCR method. Table 3 presents normalization factors.

Table 3. Normalization factors.

\begin{tabular}{|c|c|c|c|c|c|}
\hline & BOD $_{5}$ & COD & N-total & P-total & Q \\
\hline$\mu$ & 386.01 & 4170.51 & 18.83 & 2.85 & 502.58 \\
\hline$\sigma$ & 219.71 & 2665.34 & 6.45 & 1.93 & 95.53 \\
\hline
\end{tabular}

In the next step the PCs were calculated. (Table 4) presents variance, percent of total variance (explained variability) for each PC, along with cumulative explained variability.

Table 4. Variances of PCs.

\begin{tabular}{|c|c|c|c|c|c|}
\hline Parameter & $\mathbf{P C}_{\mathbf{1}}$ & $\mathbf{P C}_{\mathbf{2}}$ & $\mathbf{P C}_{\mathbf{3}}$ & $\mathbf{P C}_{\mathbf{4}}$ & $\mathbf{P C}_{\mathbf{5}}$ \\
\hline Variance & 2.21 & 1.47 & 0.85 & 0.41 & 0.06 \\
\hline Explained variability [\%] & 44.2 & 29.4 & 17.0 & 8.2 & 1.2 \\
\hline Cumulative explained variability [\%] & 44.2 & 73.6 & 90.6 & 98.8 & 100 \\
\hline
\end{tabular}

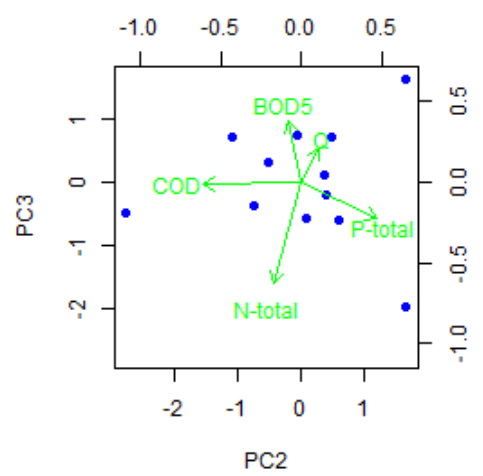

Fig. 3. View on original dataset from perspective of final model PCs. 
Only 3 first PCs were sufficient to explain $90 \%$ of the dataset variance. Those components were retained for the second step - linear regression. Additionally, the linear coefficient for $P C_{1}$ was insignificant, so it was removed from the model. The final model contained $P C_{2}$ and $P C_{3}$. Figure 3 presents a biplot - a view on 5-dimensional space of normalized original input variables, from the perspective of $P C_{2}$ and $P C_{3}$ [13]. The bottom and left axes represent $P C_{2}$ and $P C_{3}$ coordinates of observations (blue dots, fig. 3). The remaining axes represent $P C_{2}$ and $P C_{3}$ coordinates of unit vectors of the normalized original variables (green arrows, fig. 3). The final model on PC scale is presented in table 5, and graphically in Fig. 4.

Table 5. Final model parameters - PC scale.

\begin{tabular}{|c|c|c|}
\hline Parameter & Estimate & p-value \\
\hline Intercept & 217.492 & $<0,0001$ \\
\hline$P C_{2}$ & 36.473 & 0.0007 \\
\hline$P C_{3}$ & 66.403 & $<0.0001$ \\
\hline$R^{2}$ & 0.891 & \\
\hline
\end{tabular}

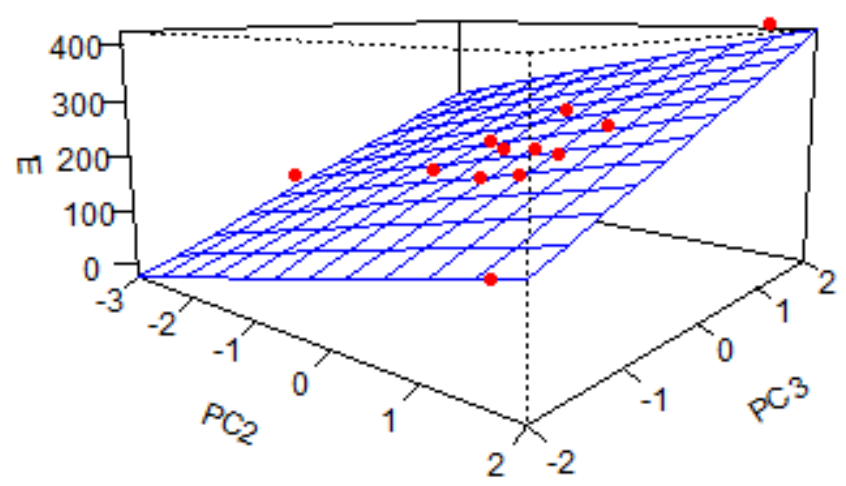

Fig. 4. Final model of energy consumption during dairy sewage pretreatment on PCs scale.

Equation (4) presents the calculated model in PCs and original input variable scale. While the second equation gives an impression that 5 variables can be set independently, from the regression point of view the whole model has only 2 degrees of freedom, not 5.

$$
\begin{aligned}
E= & 217.492+36.473 \times P C_{2}+66.403 \times P C_{3} \\
E= & 0.127 \times B O D_{5}-0.011 \times C O D-9.296 \times N_{t o t} \\
& +1.413 \times P_{t o t}+0.238 \times Q+264.920
\end{aligned}
$$

\section{Conclusions}

Dairy WWTPs usually require additional pretreatment in comparison to the municipal ones. Operations such as screening, averaging and air flotation are commonly applied and have a substantial share in the electric energy consumption in the functioning of dairy WWTPs. The analyzed data set obtained as a result of research conducted in a dairy sewage treatment plant allowed to determine the dependencies between five main technological parameters (the loads of removed pollutants and hydraulic flow) and energy consumption during 
individual pretreatment processes of dairy sewage treatment plants. The obtained model in the form of an equation allows to estimate the expected energy consumption depending on the given initial conditions. The chosen analysis model presents at the same time the mutual dependencies between these variables, exposing the actual, hidden number of parameters which control the aforementioned model.

Optimizing the process of dairy sewage pretreatment is vital not only from the energy consumption standpoint, but also has an important influence on biological processes, which are responsible for the final degree of sewage treatment and water quality in a receiver.

\section{Acknowledgements}

The research was funded by Research Project conducted in the department of Technology in Engineering and Environmental Protection No.S/WBiIŚ/3/2014, as well as with the technical and scientific cooperation between the BUT and Bielmlek Dairy Cooperative in Bielsk Podlaski, Poland.

\section{References}

1. Central Statistics Office, Statistical Yearbook of Agriculture (Statistical Publishing Establishment, Warsaw, 2017)

2. W. Dąbrowski, R. Żyłka, P. Malinowski, Envir. Res. 153 (2017)

3. S. Longo, B.M. d'Antoni, M. Bongards, A. Chaparro, A. Cronrath, F. Fatone, J.M. Lema, M. Mauricio-Iglesias, A. Soares, A. Hospido, Appl. Eng. 179 (2016)

4. L. Fitzsimons, M. Horrigan, G. McNamara, E. Doherty, T. Phelan, B. Corcoran, Y. Delaure, E. Clifford, J. Clean. Prod. 131 (2016)

5. V. Parravicini, K. Svardal, J. Krampe, Energy Procedia 97 (2016)

6. I. T. Jolliffe, ,J. R. Stat. Soc. Series C 31, 3 (1982)

7. K. Pearson, Philos. Mag. 2, 11 (1901)

8. I. Bodík, M. Kubaská, Environ. Prot. Eng. 39, 2 (2013)

9. H. Wang, Y Yang, A. A. Keller, X. Li, S. Feng, Y. Dong, F. Li, Appl. Energy, 184 (2016)

10. W. Li, L. Li, G. Qiu, J. Clen. Prod. (to be published),

11. W. Dąbrowski, R. Żyłka, M. Rynkiewicz, J. Environ. Eng. 17, 3 (2016)

12. R Core Team, $R$ : A language and environment for statistical computing. R Foundation for Statistical Computing, (Vienna, Austria. URL,2016) (https://www.R-project.org/)

13. K. R. Gabriel, Biometrika, 58 (1971) 